\title{
PELATIHAN MENDESAIN ARTIKEL ARTISTIK MENGGUNAKAN MICROSOFT WORD BAGI KELAS 5 SD DI SDIT SALSABILA AL MUTHI'IN YOGYAKARTA
}

\author{
Nurcahyani Dewi Retnowati ${ }^{1}$, Astika Ayuningtyas ${ }^{2}$, Asih Pujiastuti ${ }^{3}$, \\ Yuliani Indrianingsih ${ }^{4}$, Anton Setiawan H. $^{5}$ \\ Program Studi Teknik Informatika \\ Sekolah Tinggi Teknologi Adisutjipto \\ Jl. Janti Blok R Lanud Adisutjipto Yogyakarta \\ nurcahyanidr@stta.ac.id ${ }^{1}$,astika@stta.ac.id ${ }^{2}$, asihpuji@stta.ac.id ${ }^{3}$, \\ yulistta@gmail.com ${ }^{4}$,anton_s_h@yahoo.com ${ }^{5}$
}

\begin{abstract}
Information and Communication Technology (ICT) in today's world is needed by every community, both adults and children. Especially for children, training in the use of information and communication technology devices is needed so that children can use them later. One of them is by training the ability to design artistic articles by utilizing a word processing application, namely Microsoft Word. Microsoft Word is a word processing application that is very popular at this time, with the application can facilitate human work, one of which is in making articles. Community service activities are emphasized in the form of training on how to design artistic articles using Ms.Word software for 5th grade students at SDIT Salsabila Al Muthi'in Yogyakarta. It is expected that the training, students can know more about artistic design techniques by utilizing Microsoft Word and its use so that it can help when doing school work and improve creativity. The results of the service activities carried out provide experience and skills to students at SDIT Salsabilla Al-Muthi'in in designing artistic articles using Microsoft Word. Thus, the implementation of community service activities with the title "Artistic Article Design Training Using Microsoft Word For Class 5 Elementary Schools in SDIT Salsabila Al Muthi'in Yogyakarta" provides significant benefits for improving students' skills in utilizing information technology and computers, especially to make artistic article.
\end{abstract}

Keywords: Artistic, Articles, Microsoft Word, Creativity

\begin{abstract}
Abstrak
Teknologi Informasi dan Komunikasi (TIK) pada jaman sekarang sangat dibutuhkan oleh setiap masyarakat baik itu orang dewasa maupun anak-anak. Khususnya pada anak-anak, sangat dibutuhkan pelatihan penggunaan perangkat teknologi informasi dan komunikasi agar nantinya anak-anak dapat memanfaatkannya dengan baik. Salah satunya adalah dengan melatih kemampuan mendesain artikel artistik dengan memanfaatkan aplikasi pengolah kata yaitu Microsoft Word. Microsoft Word adalah aplikasi pengolah kata yang sangat populer pada saat ini, dengan aplikasi tersebut dapat memudahkan kerja manusia, salah satunya dalam membuat artikel. Kegiatan pengabdian pada masyarakat dititik beratkan dalam bentuk pelatihan tentang cara mendesain artikel artistik menggunakan software Ms.Word bagi siswa-siswi kelas 5 di SDIT Salsabila A1 Muthi'in Yogyakarta. Diharapkan dengan adanya pelatihan tersebut, siswa-siswi dapat lebih mengetahui tentang teknik mendesain yang artistik dengan memanfaatkan Microsoft Word dan penggunaannya sehingga dapat membantu saat pengerjaan tugas sekolah
\end{abstract}


maupun meningkatkan kreativitas. Hasil dari kegiatan pengabdian yang dilaksanakan memberikan pengalaman dan ketrampilan pada para siswa di SDIT Salsabilla Al-Muthi'in dalam mendesain artikel yang artistik dengan memanfaatkan Microsoft Word. Dengan demikian, pelaksanaan kegiatan pengabdian kepada masyarakat dengan judul "Pelatihan Mendesain Artikel Artistik Menggunakan Microsoft Word Bagi Kelas 5 SD di SDIT Salsabila Al Muthi'in Yogyakarta" memberikan manfaat yang signifikan bagi peningkatan keterampilan siswa siswi dalam memanfaatkan teknologi informasi dan komputer, khususnya untuk membuat artikel artistik.

Kata Kunci: Artistik, Artikel, Microsoft Word, Kreativitas

\section{Latar Belakang Masalah}

SDIT Salsabilla Al-Muthi'in merupakan salah satu sekolah dasar yang berbasis Islam Terpadu yang berada di kawasan Banguntapan, Bantul Provinsi Daerah Istimewa Yogyakarta. Jumlah siswa sampai tahun 2018 ini sebanyak 41 orang, dengan rincian jumlah siswa per kelasnya sesuai yang ada pada Tabel 1 Untuk konten mata pelajaran yang digunakan sudah berbasis kurikulum 2013, di mana salah satunya adalah mata pelajaran Prakarya yang memuat Teknologi Informasi Komputer.

Tabel 1. Jumlah Siswa SDIT Salsabilla Al-Muthi'in 2018

\begin{tabular}{|c|c|}
\hline Kelas & Jumlah Siswa \\
\hline 1 & 54 \\
\hline 2 & 54 \\
\hline 3 & 52 \\
\hline 4 & 44 \\
\hline 5 & 41 \\
\hline 6 & 17 \\
\hline
\end{tabular}

Pada proses pembelajaran TIK setiap tatap mukanya di SDIT Salsabilla AlMuthi' in menggunakan model ceramah, dengan anak-anak memperhatikan langsung Guru menjelaskan setiap materi, dan kemudian mempraktikkannya secara bergantian di depan kelas satu per satu anak. Hal tersebut tentunya kurang maksimal bila dijadikan latihan untuk meningkatkan ketrampilan anak-anak dalam memahami materi yang disampaikan. Salah satunya adalah tentang bagaimana membuat desain artikel artistik yang menunjang proses pembelajaran yang saat ini sudah berbasis kurikulum 2013. Pada SDIT Salsabilla Al-Muthi'in sendiri fasilitas komputer yang disediakan terbatas, dengan kata lain belum mencukupi dengan jumlah siswa yang mengikuti kelas TIK. Sehingga dalam mempraktikkannya harus saling bergantian setiap siswa. Di samping itu, bahan ajar yang digunakan oleh guru masih terbatas jumlah sehingga perlu dilakukan penambahan resource materi sebagai penunjang kegiatan pembelajaran.

Berdasarkan analisis situasi dan permasalahan mitra di atas, kegiatan pengabdian ini menjadi solusi kebutuhan para siswa di SDIT Salsabilla Al-Muthi' in, melihat kondisi yang terjadi, perlu adanya pelatihan khusus yang menyediakan ruang untuk anak-anak mempraktikkan materi TIK yang pernah didapatkannya. Praktik ini bersifat mandiri, artinya setiap anak memegang satu komputer dengan harapan pemahaman dan pengujian materi lebih maksimal. Selain itu, memberi pengalaman pada anak-anak dalam mengimplementasikan dan mengembangkan materi TIK secara mandiri yang mendukung proses pembelajaran pada kurikulum 2013. Kegiatan pengabdian pada masyarakat dititikberatkan dalam bentuk pelatihan cara mendesain artikel artistik dengan 
memanfaatkan aplikasi pengolah kata yaitu Microsoft Word. Pengabdian ini merupakan kesinambungan dari pengabdian yang sudah dilakukan sebelumnya [1][2].

\section{Metodologi Penelitian}

Kegiatan yang dilaksanakan berupa pendampingan dalam bentuk pelatihan menggunakan Microsoft Word untuk membuat desain artikel artistik. Materi pelatihan disesuaikan dengan kebutuhan para siswa yang menunjang pada proses pembelajaran di kurikulum 2013. Desain artikel artistik dapat didefinisikan secara umum, yaitu membuat artikel lebih menarik dengan teknik seni yang antara lain menyajikan grafik, gambar dan jenis font sehingga pembaca lebih tertarik [3][4][5].

Pada tahapan pertama, tim pelaksanaan pengabdian melakukan beberapa kegiatan, di antaranya koordinasi para pelaksana untuk menyiapkan tempat dan perlengkapan guna mendukung terlaksananya pelatihan, kemudian tim pelaksana melakukan koordinasi dengan para peserta yaitu guru dan siswa siswi kelas 5 SDIT Salsabilla Al Muthi'in untuk penyebaran undangan pelaksanaan pendampingan. Langkah berikutnya mempersiapkan modul pelatihan penggunaan Microsoft Word untuk membuat desain artikel artistik bagi siswa siswi kelas 5 dengan rincian materi seperti yang terlihat pada Tabel 1.

Tabel 1. Topik Materi Pada Modul Pelatihan

\begin{tabular}{|c|l|}
\hline No. & \multicolumn{1}{|c|}{ Topik } \\
\hline 1. & Membuat Font Menarik Menggunakan WordArt \\
\hline 2. & Menambahkan Gambar atau Bentuk Ke Dalam Artikel \\
\hline 3. & Membuat Grafik (Chart) \\
\hline 4. & Penggunaan Tools Page Breaks dan Header Footer \\
\hline 5. & Membuat Format Layout Artikel \\
\hline
\end{tabular}

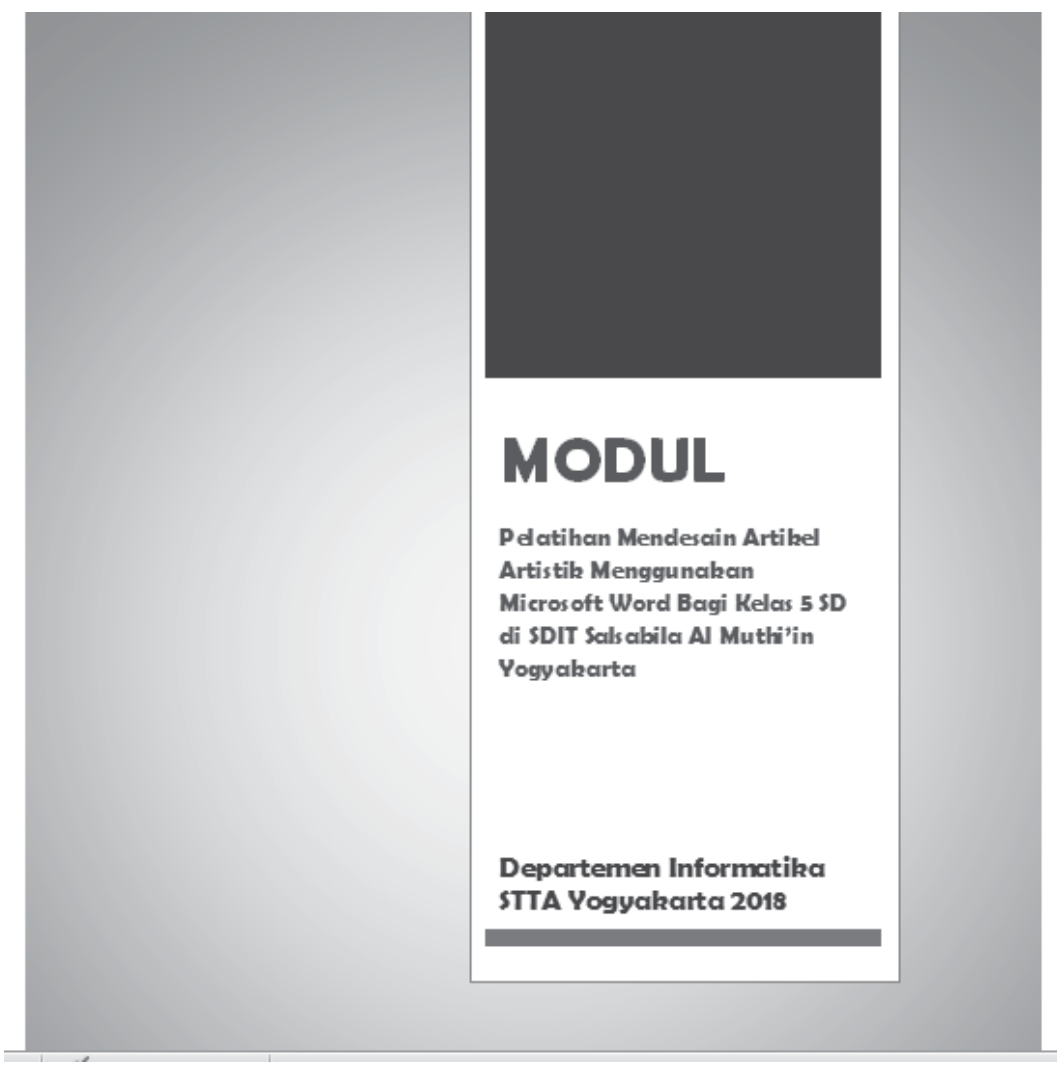

Gambar 1. Tampilan Cover Modul Pelatihan 
Untuk mengukur tingkat keberhasilan kegiatan pendampingan pelatihan penggunaan Microsoft Word untuk membuat desain artikel artistik bagi siswa siswi kelas 5 ini, peserta diberikan latihan untuk membuat desain artikel yang artistik sesuai dengan pengajaran pada kurikulum 2013 dalam bentuk softcopy berektensi .doc. Tahap ini dimaksudkan untuk mengetahui kemampuan para siswa dalam memanfaatkan aplikasi yang diajarkan untuk membuat desain artikel yang artistik.

\section{Hasil dan Pembahasan}

Pendampingan pelatihan penggunaan Microsoft Word untuk membuat desain artikel artistik bagi siswa siswi kelas 5 SDIT Salsabilla Al Muthi' in dengan menggunakan Microsoft Word dilaksanakan di Laboratorium Multimedia Sekolah Tinggi Teknologi Adisutjipto (STTA) Yogyakarta pada bulan Mei 2018. Pendampingan dilaksanakan selama sembilan jam, sesuai waktu yang ditargetkan. Peserta kegiatan berjumlah empat puluh satu siswa.

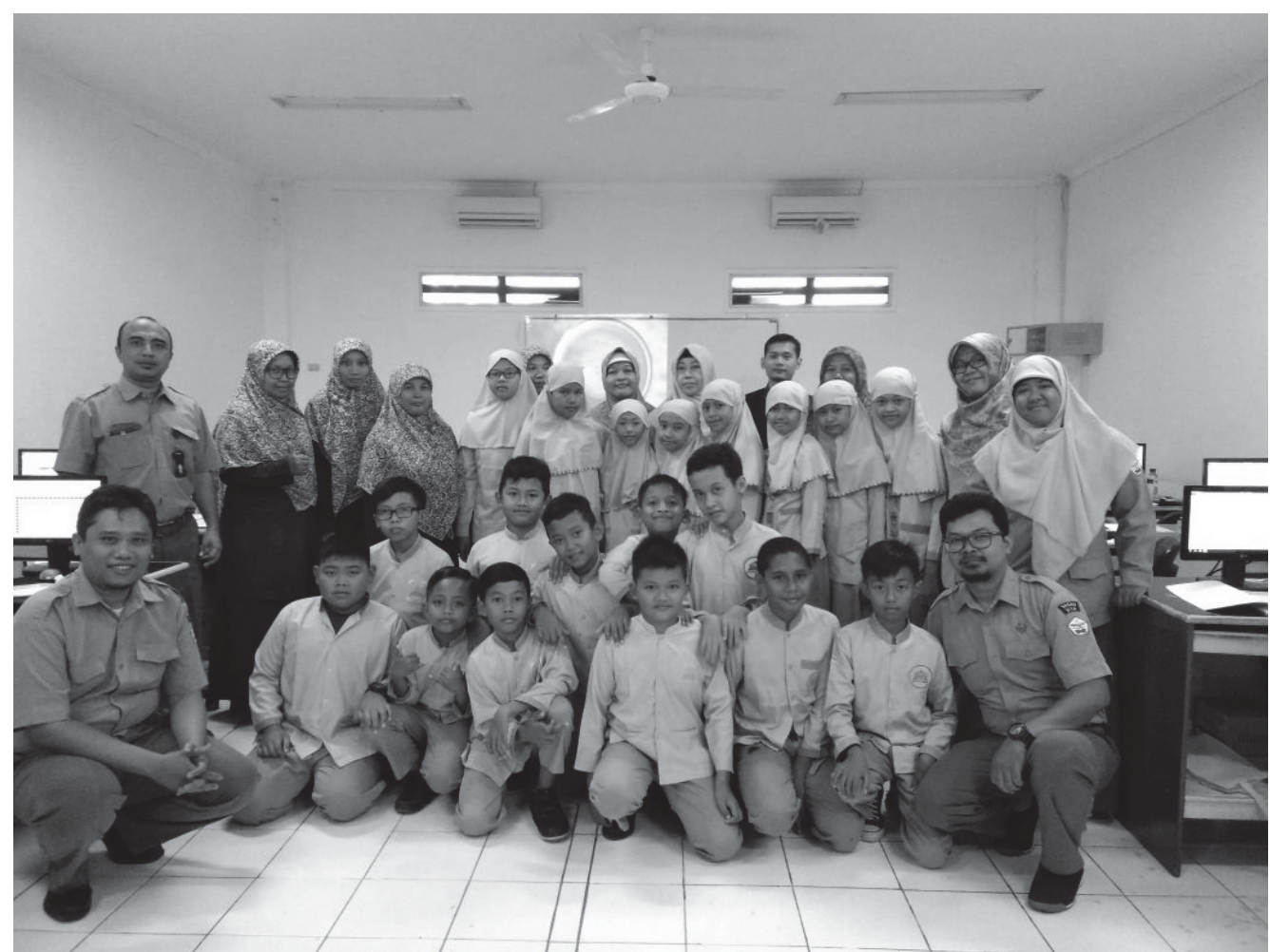

\section{Gambar 2. Tim Pelaksana dan Peserta Pengabdian Kepada Masyarakat Hari Pertama}

Jumlah peserta pengabdian secara keseluruhan adalah dua puluh lima orang yang berasal dari SDIT Salsabilla Al Muthi' in Yogyakarta. Kedua puluh lima orang tersebut merupakan dua puluh satu siswa klas 5 Sekolah Dasar (SD), tiga orang guru pendamping dan satu Kepala Sekolah SDIT Salsabila Al Muthi'in (Gambar 2 s.d 4). Kegiatan diawali dengan pemberian sambutan oleh Kepala Departemen Informatika STTA Yogyakarta dan di hari terakhir pendampingan ditutup dengan pemberian kenang-kenangan dari Departemen Informatika STTA kepada SDIT Salsabilla Al Muthi'in (Gambar 5 s.d 7). 


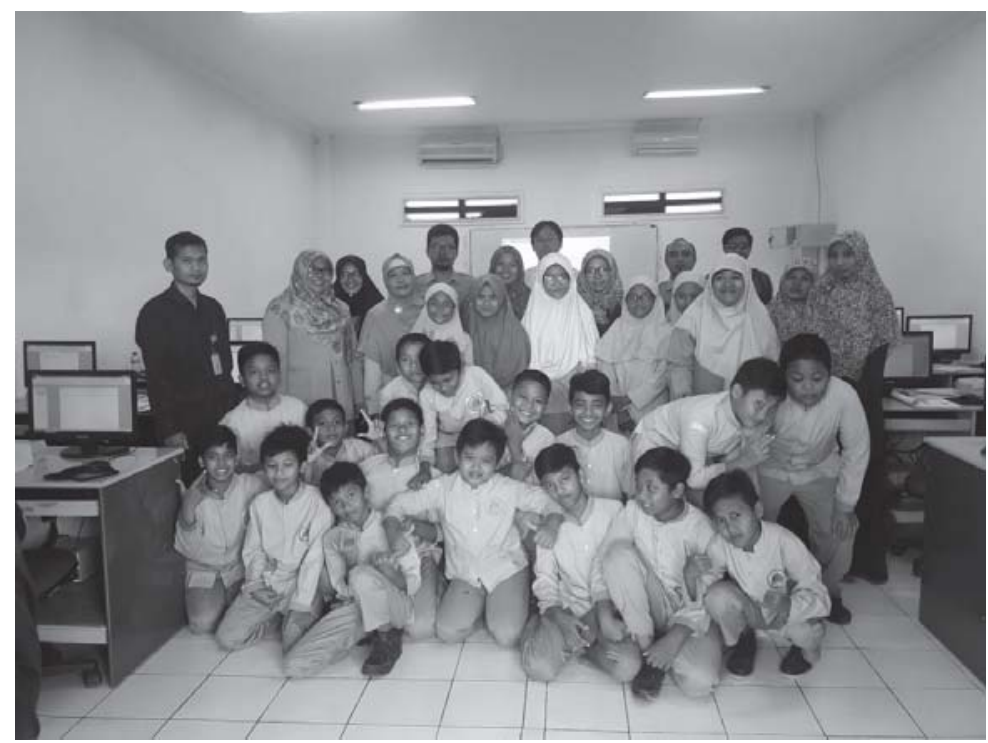

Gambar 3. Tim Pelaksana dan Peserta Pengabdian Kepada Masyarakat Hari Kedua

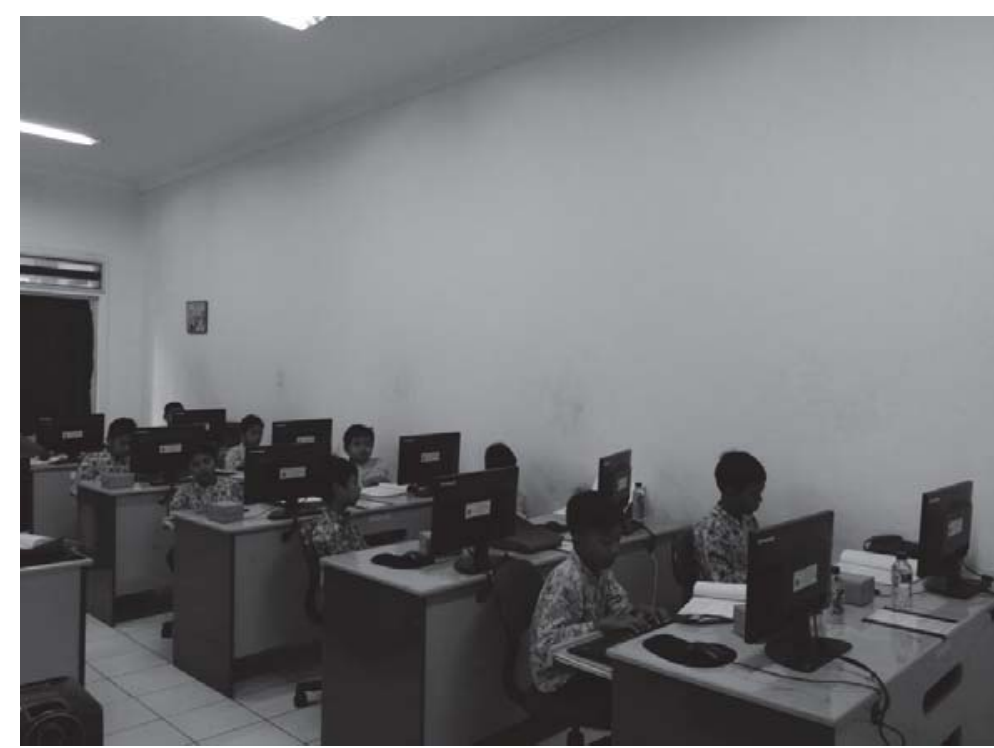

Gambar 4. Kegiatan Peserta Pengabdian Kepada Masyarakat

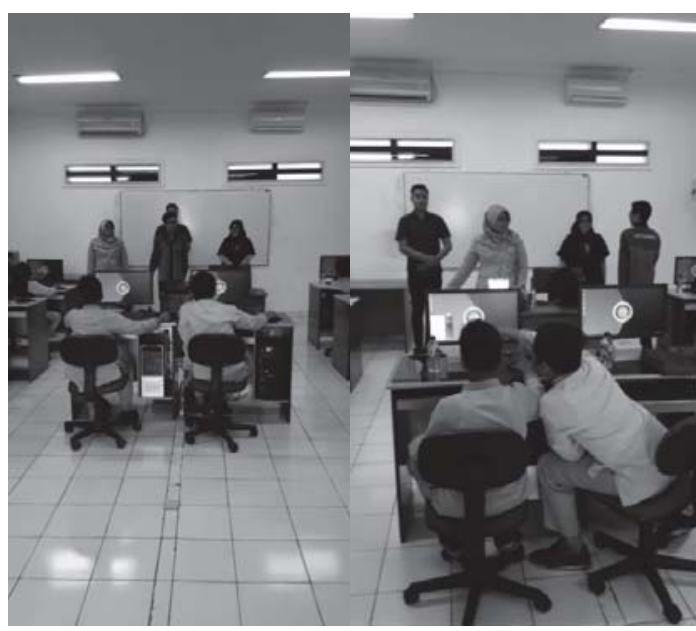

Gambar 5. Pembukan Kegiatan Pengabdian Kepada Masyarakat 


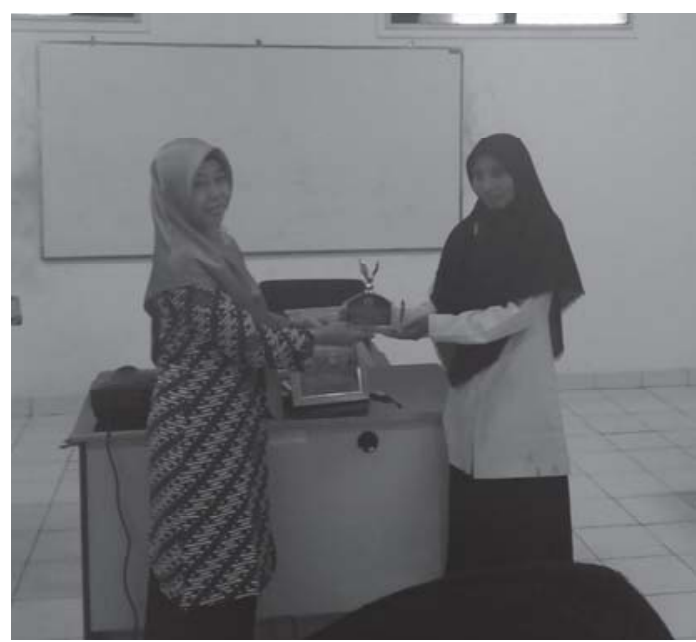

\section{Gambar 6. Penutupan Kegiatan Pengabdian Kepada Masyarakat}

Setelah materi pelatihan selesai, pada hari terakhir disediakan waktu kurang lebih dua jam untuk para peserta mengerjakan latihan guna menguji pemahaman materi secara keseluruhan. Adapun setiap peserta diminta membuat desain artikel artistik sesuai kreativitas masing-masing. Salah satu contoh hasil pembuatan desain artikel artistik dapat dilihat pada Gambar 7 dan Gambar 8.

\begin{tabular}{|c|c|c|c|}
\hline \multirow{2}{*}{ Nama } & \multicolumn{3}{|c|}{ Warna Kelereng } \\
\cline { 2 - 4 } & Merah & Hijau & Biru \\
\hline Andi & 8 & 25 & 15 \\
\hline Budi & 18 & 20 & 25 \\
\hline Banu & 15 & 8 & 20 \\
\hline Dito & 20 & 13 & 30 \\
\hline
\end{tabular}

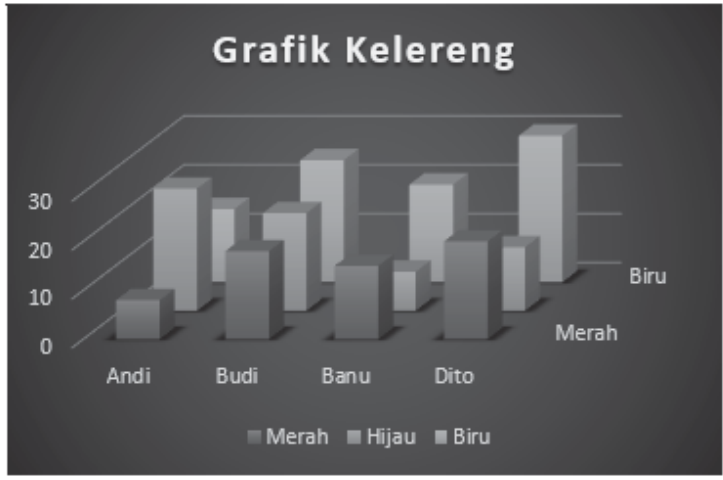

Gambar 7. Contoh Pertama Hasil Latihan Peserta

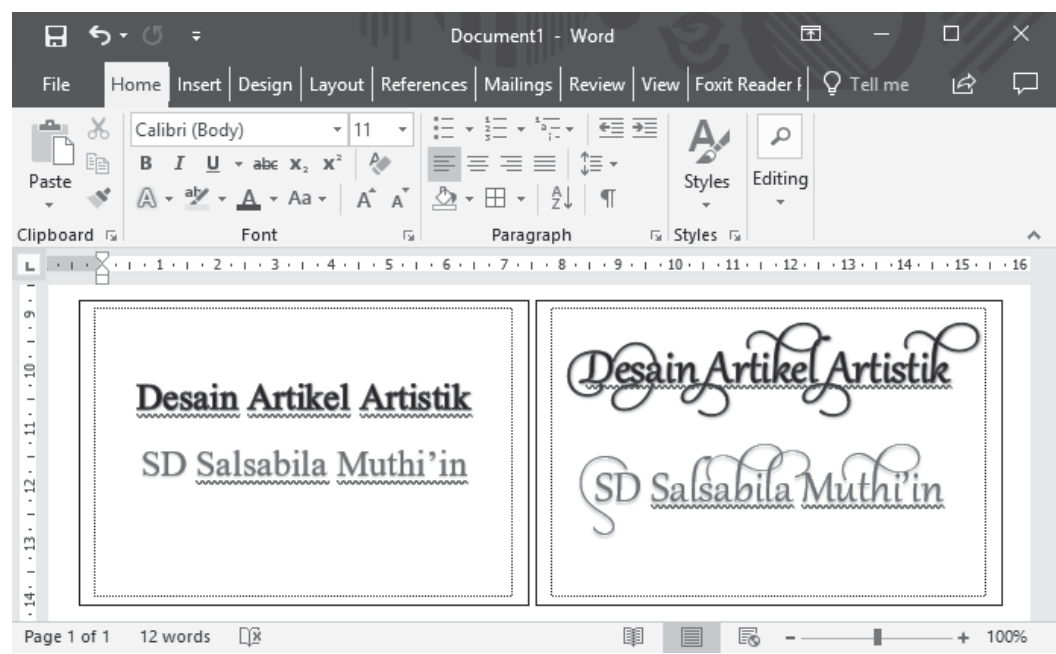

Gambar 8. Contoh Kedua Hasil Latihan Peserta 
Tabel 2 .

Hasil penilaian terhadap latihan yang dikerjakan para siswa dapat dilihat pada

Tabel 2. Hasil Penilaian Latihan Siswa

\begin{tabular}{|c|c|c|c|c|}
\hline \multirow[t]{2}{*}{ No. } & \multirow[t]{2}{*}{ Nama } & \multicolumn{3}{|c|}{ Hasil Penilaian } \\
\hline & & Kurang & Cukup & Baik \\
\hline 1. & Lysandra Mutia K. W. & & $\mathrm{V}$ & \\
\hline 2. & Syafana Ramandari & & & $\mathrm{V}$ \\
\hline 3. & M. Misbahul Munir & & $\mathrm{V}$ & \\
\hline 4. & Faunia Nadi Raudha & $\mathrm{V}$ & & \\
\hline 5. & Khansa Nadia Gadi Saputri & & $\mathrm{V}$ & \\
\hline 6. & Jihan Tiara Radita Putri & & & $\mathrm{v}$ \\
\hline 7. & Lambang Wicaksono & & $\mathrm{V}$ & \\
\hline 8. & Altaf Surya Annawaf & & $\mathrm{V}$ & \\
\hline 9. & Muhamad Alvin Wardani & & & $\mathrm{v}$ \\
\hline 10. & Faiq Al Giffari & & $\mathrm{V}$ & \\
\hline 11. & Adnan M.R & & $\mathrm{V}$ & \\
\hline 12. & Gautama Farrel N. A. & & & $\mathrm{V}$ \\
\hline 13. & Farhan Dwi Antoro & & & $\mathrm{v}$ \\
\hline 14. & Hafiz Fuqan Nauval & & & $\mathrm{V}$ \\
\hline 15. & Azzaki Mushthofa Insani & & & $\mathrm{V}$ \\
\hline 16. & Muhammad Fauzan D. A. & & $\mathrm{V}$ & \\
\hline 17. & Figo Ahsan Biantara & & & $\mathrm{V}$ \\
\hline 18. & Muhammad Ihsan Putra & & & $\mathrm{V}$ \\
\hline 19. & Maheswara Helga Rararya & & & $\mathrm{v}$ \\
\hline 20. & Axello Daiva Jagadhita & & & \\
\hline 21. & Fadhil Azzufar Al Ghozali & & $\mathrm{V}$ & \\
\hline 22. & Vania Sani Atmoko & & $\mathrm{V}$ & \\
\hline 23. & Afifah Khoirina Azahra & & & $\mathrm{V}$ \\
\hline 24. & Ivory Aurellia Putri & & & $\mathrm{V}$ \\
\hline 25. & Salsa Budi Setyanti & & & $\mathrm{V}$ \\
\hline 26. & Asma Fathiyya & & & $\mathrm{V}$ \\
\hline 27. & Laila Aulani Nursiam & & & $\mathrm{V}$ \\
\hline 28. & Cheryl Makaila Fasya & & $\mathrm{V}$ & \\
\hline 29. & Ghaitsaa Zulfa Hasanah & & & $\mathrm{V}$ \\
\hline 30. & Hafizh Rachmanindra & & & $\mathrm{v}$ \\
\hline 31. & Hudson Ali Firdaus & & & $\mathrm{V}$ \\
\hline 32. & Latif Lukman Rabani & & $\mathrm{V}$ & \\
\hline 33. & Dzaki Taufiqurahman S. & & $\mathrm{V}$ & \\
\hline 34. & Muhammad Khoirurroziqin & & $\mathrm{V}$ & \\
\hline 35. & Erlangga Putra Wardhana & & & $\mathrm{v}$ \\
\hline 36. & Nabil Azfa Aminuddin & & & $\mathrm{V}$ \\
\hline 37. & Zaidan Alam & & & $\mathrm{V}$ \\
\hline 38. & Farras Risqy A.H.S. & & $\mathrm{V}$ & \\
\hline 39. & Fadhil Islamilovic & & $\mathrm{V}$ & \\
\hline 40. & Farid Akmal Maulana & & & $\mathrm{V}$ \\
\hline 41. & Izza Imam Akbar & & $\mathrm{V}$ & \\
\hline
\end{tabular}

Hasil penilaian dari latihan yang telah dikerjakan oleh para siswa menunjukkan bahwa 1 orang siswa $(2,43 \%)$ masih kurang dalam membuat artikel artistik, 17 orang 
siswa (41,46\%) dapat membuat artikel artistik, dan 22 orang siswa $(53,65 \%)$ sudah baik dalam membuat artikel artistik. Jika dilihat dari keseluruhan, para siswa sudah dapat membuat artikel artistik.

\section{Kesimpulan}

Kegiatan pengabdian kepada masyarakat berupa pelatihan mendesain artikel artistik menggunakan Microsoft Word bagi siswa kelas 5 SD di SDIT Salsabilla Al Muthi'in Yogyakarta yang diselenggarakan oleh Dosen Departemen Informatika STTA Yogyakarta mampu memberikan kontribusi positif terhadap peningkatan kemampuan serta kreativitas para peserta (siswa kelas 5 SD) dalam penggunaan Microsoft Word, khususnya untuk pembuatan desain artikel yang artistik. Untuk kedepannya perlu dikembangkan lagi kterampilannya dalam memanfaatkan teknologi informasi dan komputer pada contoh aplikasi yang lain, seperti Microsoft Power Point, Corel Draw, Macromedia Flash, sehingga terwujud peningkatan keterampilan yang dapat mendukung pembuatan bahan ajar bagi siswa yang menunjang proses pembelajaran pada kurikulum 2013.

\section{Daftar Pustaka}

[1] Ayuningtyas, A., Honggowibowo, A. S., Pujiastuti, A., Retnowati, N. D., \& Indrianingsih, Y. (2018). Pendampingan Pembuatan Bahan Ajar Bagi Guru Sekolah Dasar Islam Terpadu (SDIT) Salsabila Al Muthi'in Berbasis Multimedia dengan Menggunakan Microsoft Power Point. KACANEGARA Jurnal Pengabdian pada Masyarakat, 1(1), 1-6.

[2] Nugraheny, D., Wintolo, H., \& Kusumaningrum, A. (2018). Pendampingan Pembuatan Bahan Ajar Berbasis Multimedia Menggunakan Macromedia Flash Bagi Para Guru SD IT Salsabila Al Muthi'in, Yogyakarta. KACANEGARA, 1(1), 23-28.

[3] Jarot, S., Shenia, A., \& Sudarma, S. (2012). Buku Pintar Microsoft Office 2007 \& 2010: Word-Excel-PowerPoint. MediaKita.

[4] https://www.slideshare.net/artnugraha/aspek-artistik-dalam-artikel-ilmiah

[5] http://blogamka.blogspot.com/2011/10/membuat-tulisan-artistik-pada-word2010.html 